\title{
Self-reported fall and associated factors among adult people with visual impairment in Gondar, Ethiopia: a cross- sectional study
}

Moges Gashaw ${ }^{1 *}$, Balamurugan Janakiraman ${ }^{1}$, Amare Minyihun ${ }^{2}$, Gashaw Jember $^{1}$ and Kedir Sany ${ }^{1}$

\begin{abstract}
Background: Fall is a major public health problem and potentially disabling issue. A vast burden of visually impaired live in low-middle income countries particularly in Sub-Saharan Africa. Limited ability to detect environmental hazards puts visually impaired at a greater risk of falls and unintentional injuries. Falls among visually impaired is associated with considerable disability, health care cost, loss of independence, and socio-economic consequences. Ethiopia lacked estimates of fall among any vulnerable population, particularly among visually impaired people. Therefore, this study aimed to estimate the prevalence of falls and factors associated among adult people with medically diagnosed visual impairment in Ethiopia.

Methods: An institutional-based cross-sectional study was conducted among visually impaired adults who attended the ophthalmology clinic at the University of Gondar comprehensive specialized hospital during the study period. Data were collected by interview method using structured questionnaires, patient medical record reviews, and physical measurements. Bivariate and multivariable binary logistic regression model analysis was used to identify factors associated with falls. Adjusted odds ratio with corresponding 95\% confidence intervals were computed to show the strength of association.
\end{abstract}

Results: A total of 328 adults medically diagnosed with visual impairment participated in the study (97.3\% response rate). The age of the participants ranged from 25 to 89 years with a mean age of ( $56.46 \pm 14.2$ years). The overall cumulative prevalence of self-reported falls among adults with visual impairment was $26.8 \%$ with $95 \% \mathrm{Cl}(22.7$, 32.4\%). The major associated factors of fall identified by multivariate analysis were; visual impairment in both eye (AOR 3.21, 95\% Cl 1.11, 9.29), fear of falling: some concerned: (AOR, 4.12; 95\%Cl, 1.44, 11.76), very concerned fear (AOR 10.03; 95\% Cl, 3.03, 33.21), medications: (AOR 4.63; 95\% Cl 2.14, 10.00) and self-reported depression: (AOR 3.46; $95 \%$ Cl 1.11, 10.79).

\footnotetext{
* Correspondence: mogesgashaw1@gmail.com

'Department of Physiotherapy, School of Medicine, College of Medicine and Health Sciences, University of Gondar comprehensive specialized hospital, University of Gondar, P.O. Box: 196, Gondar, Ethiopia

Full list of author information is available at the end of the article
}

(c) The Author(s). 2020 Open Access This article is licensed under a Creative Commons Attribution 4.0 International License, which permits use, sharing, adaptation, distribution and reproduction in any medium or format, as long as you give appropriate credit to the original author(s) and the source, provide a link to the Creative Commons licence, and indicate if changes were made. The images or other third party material in this article are included in the article's Creative Commons licence, unless indicated otherwise in a credit line to the material. If material is not included in the article's Creative Commons licence and your intended use is not permitted by statutory regulation or exceeds the permitted use, you will need to obtain permission directly from the copyright holder. To view a copy of this licence, visit http://creativecommons.org/licenses/by/4.0/ The Creative Commons Public Domain Dedication waiver (http://creativecommons.org/publicdomain/zero/1.0/) applies to the data made available in this article, unless otherwise stated in a credit line to the data. 
(Continued from previous page)

Conclusion: The result of this study indicates a moderate self-reported prevalence of fall among adult people with medically diagnosed visual impairment. Identifying sub-groups at risk of falls among visually impaired, modifiable risk factors, implementation of precaution measures to avoid fall and fall-related injuries, and most importantly measures that would reduce the fear of falls in visually impaired people deserves immediate attention.

Keywords: Fall, Visual impairment, Medications, Depression, Fear of fall, Ethiopia

\section{Background}

Falls are a major public health problem and an estimated 646,000 fatal falls occur each year. It is also one of the leading causes of unintentional injury-related death and can cause substantial morbidity [1,2]. Visual impairment is reported to be an independent risk factor for falls and fall-related death among adults aged over 50 years [3]. Fear of falling that precede or results from falls is a distinct health outcome and the process can sometimes become a vicious circle. Fear of falling is a low perceived ability to avoid falling while performing routine actives of daily living and has been associated with self-imposed restrictions in physical activity and social participation $[4,5]$.

Visual impairments reduce one's ability to detect hazards in the environment and have a drastic impact on the physical, psychological, and socio-economically development of individuals and societies [6]. Visual impairment is more prevalent in low and middle-income countries (LMICs), about 80-90\% of the world's visually impaired people live in LMICs [7]. In Sub-Saharan African countries, about 70 million people had been reported to live with visual impairment and Ethiopia is believed to have one of the world's highest rates of blindness and low vision, of which about $80 \%$ is preventable or treatable $[8,9]$.

Studies had reported a wide range of risk factors for fall; age, gender, severity of visual impairment, body mass index, psychosocial, physical environment, fear of fall, depression, decreased vestibular reflexes, decreased muscle strength, increasing postural sway, concurrent medical issues, poly-medications, and pre-existing medical co-morbidities [2, 10, 11]. Polypharmacy is also one of the important risk factor for falling and the association is stronger if the medications include fall riskincreasing medications [12].

In particular, fear of fall among people with eye diseases has been related to higher chances of falls. Fear of fall can lead to loss of confidence, depression, activity avoidance, reduced social interaction, and disability. Therefore, fear of falling is a key variable in order to understand factors with fall risks and for the development of prevention strategies [13-15].

Falls among visually impaired adults can occur due to multifaceted intrinsic and extrinsic factors. In LMICs people with visual impairment are confronting a different set of challenges like accessibility barriers, navigator barriers, unemployment, health care utility challenges, and societal stigma [16, 17]. Though, population-based studies had reported that old age and related-poor vision as a frequent risk factor for fall, yet the knowledge about visual-related clinical characteristics in falls among adults living in LMICs is sparse. Estimates of falls and their predictors are largely unexplored in any population in Ethiopia and more importantly in the visually impaired population who are at a greater risk of falls and related morbidity. Hence, to gain an understanding of the factors associated with this population living in LMICs like Ethiopia is crucial. This study is a preliminary attempt to determine the burden of falls, and associated factors among adult people living with visual impairment in Ethiopia. Thus this evidence will help us to establish preventive measures among this population in Ethiopia.

\section{Methods}

\section{Study design, setting, and participants}

An institutional-based cross-sectional study was conducted from January to June 2018 among adults with medically diagnosed visual impairment who seek care from the ophthalmology clinic at the University of Gondar comprehensive specialized hospital (UoGCSH), North West Ethiopia during the study period. This eye care center provides a comprehensive clinical and community eye health services free of cost for eight zones and serves as a major referral center for 14 million people living in and around Gondar, North West Ethiopia. It is estimated that a minimum of 4720 patients utilizes different eye care service per year and this is the only clinical catchment area for visually impairment individuals in Gondar city. Based on the 2016 population estimate of Gondar city administration bureau had a total population of 335,000 . The study area is geographically a challenging mountainous terrain and unsafe sometimes even for normal-sighted people and hazardous for susceptible people like older, physically challenged and people with visual impairment. The study setting (UoGCSH), the ophthalmic outpatient clinic receives a wide range of ambulatory VI patients visiting for the consultation, laboratory testing, 
medications, eye-glasses, mobility aids, and surgery appointments and the study setting is the only referral hospital for the entire Gondar city. Hence, individuals with a wide spectrum of visual impairment visit this institution. As of 2017, the ophthalmic clinic cares for 40 to 60 visually impaired patients every day. So, an average of 1500 adult participants is expected to visit the clinic during the 6 weeks data collection period.

Adults with medically diagnosed visual impairment in one or both eyes, those who can walk independently with or without mobility aids, aged $\geq 18$ years with hearing ability were included in this study.

\section{Sample size determination and sampling procedure}

The sample size required for this study was determined using the single population proportion formula [18] and calculated using Epi Info software version7.0 (Centres for Disease Control and Prevention, USA). The samples were obtained from a relatively small population $(N=$ 1500). The following assumptions were used to determine the required sample: prevalence of $50 \%$ since no past regional data exists, a confidence level of $95,5 \%$ margin of error. The derived power calculated sample size was $n=306$. Accounting for an estimated refusal or non-response rate of $10 \%$, the final sample size was calculated to be $n=337$.

The study participants were recruited by using a systematic random sampling method by arranging the patients based on their chart number from the registered appointment register selected in $\mathrm{K}^{\text {th }}$ interval each day during the study period. The first patient between 1 and $\mathrm{K}$ was selected randomly by a lottery method, and the next patient was interviewed every fourth interval. The procedure was repeated until the estimated eligible sample size was reached.

\section{The operational definition}

Self-reported fall in the past12 months was defined as an event that results in a person coming to rest unintentionally on the ground or other lower level, not a result of acute illness, at least once in the past 12 months [19]. Fear of fall was assessed by close-ended a question phrased as: "Are you afraid or concerned about falling while performing activities of daily living (ADL)?" [20]. Visual impairment (in any eye); significant loss of vision on which Snellen's chart reading is less than $6 / 12$ to no light perception, Mild visual impairment; presenting with a visual acuity of less than 6/12(20/40) greater than or equal to 6/18(20/60). Moderate visual impairment; presenting with visual acuity of less than $6 / 18(20 / 60)$ to greater than or equal to $6 / 60(20 / 200)$ and severe visual impairment is presenting with visual acuity of less than $6 / 60(20 / 200)$ to no light perception. Visual impairment, which could not be eliminated by refractive correction or lenses (non-correctable) [8].

\section{Study procedure}

This cross-sectional study was approved by the Gondar University School of Medicine research and ethical review committee (SOM 2310706). After providing a verbal account and explaining about this study to the participants with visual impairment, the written informed consent statement was obtained. A structured data collection questionnaire was developed based on an extensive review of related studies [21-24]. The questionnaire was initially prepared in English and then translated to Amharic and back to English by language experts at University of Gondar and checked for the consistency of the questions and corrections were made accordingly.

The questionnaire included domains like sociodemographic characteristics: age, gender, behavioral characteristics: physical measurements, visual related characteristics, medical co-morbidity, and fall-related characteristics including fall-related injuries (Additional file 1). A review of the participant's hospital records for laboratory investigations results, medications, and medical illnesses were done. And thereafter, the selected participant was referred to the ophthalmology clinic for visual assessment. The questionnaires were orally administered to each study participant individually during the interview by four trained ophthalmic nurses and the responses of the patient were recorded in the data collection sheet. Factors related to visual impairment, visual acuity measurement, Snellen's E chart measurement, and medical eye screening reports evaluated by the optometrist on the day of data collection was recorded by the data collector.

Counter checking of the daily filled questionnaires and regular supervision was done by MG and BJ. The questions were read aloud and the participant's responses were recorded. To avoid any bias that may have affected the participants' responses the questions were read for each participant individually in a quiet room and they were told to repeat the questions again to the data collector to assure the reception of questions clearly. The data collectors made sure that the questions were simplified as much as possible, caregivers were accompanied during self-reporting, and explanations were given whenever a question aroused.

\section{Data processing and analysis}

Data were checked for completeness and entered into Epi-Info version 7.1 and then exported to IBM SPSS version 20 statistical software for coding, recoding, storing and further analysis. Descriptive statistics like frequencies, percentages, means, and standard deviations were 
used for all participant characteristics and factors associated with falls. With self-reported falls in the past 12 months (categorized as none versus present) as the dependent variable, logistic regression analyses were done to determine the association with different independent variables. Independent variables included in the regression models were socio-demographic characteristics: age in years (categorized: adults 18-44, older adults 45-64, and elders >64), gender, residence (categorized urban, rural), marital status (categorized not married, married, divorced, widowed), level of education (categorized no formal school, primary, secondary, diploma and above), occupation (categorized homemaker, farmer, civil servant, merchant, retired, others), income (categorized $<1000,1000-2000,>2000-<3000,>3000$ in Ethiopian birr per month), physical measurements like height, weight, BMI (categorized: underweight, normal weight, overweight, and obese), behavioral factors: alcohol drinking (categorized never, past, current), smoking (categorized never, past, current), self-reported regular physical exercise (none, present). Psychosocial factors: fear of falling (categorized not at all concerned, somewhat concerned, and very concerned), social support (yes, no), depression (yes, no). Vision and health-related factors: mild vision impairment, moderate vision impairment, severe vision impairment, and eye involved (one versus both), current level of mobility, comorbid, drug in-take, place of fall, and activity during fall.

Prior to conducting the regression model the following assumptions were tested: multicollinearity (Variance inflation factor $<10$ ) independence of residuals by scatter plots. Initially, bivariate analysis was conducted and independent variables that were found statistically significant were fitted into the multivariate model using the backward stepwise (likelihood ratio) method.

We tested for potential statistically significant interactions by adding the product of the covariates in the multivariable-adjusted logistic regression models. Crude and adjusted odds ratios and $95 \%$ confidence intervals were calculated from univariate and multivariate logistic models for associations between the independent variables and the dependent variable. Variables were entered into the model using forced entry and categories were used as covariates for detailed analyses. Results were considered statistically significant when $95 \%$ confidence intervals not containing unity ( $p$-value $<0.05)$ for both main effects and interaction terms. Interaction terms were used to examine the potential association between fear of fall and fall differed by hypothesized variables, including age category, the severity of visual impairment, depression, eye involved, and medication intake. When clear sub-groups seemed to be present in the dataset, significance testing (Pearson $\chi^{2}$ ) and, if appropriately sized subgroups per category remained, logistic regression analyses were conducted. Finally, the research was checked for the adherence to STROBE guidelines (Additional file 2).

\section{Results}

Socio-demographic and behavioral characteristics

A total of 337 participants were approached for participation. Among those 328 visually impaired adults consented to participate and completed the questionnaire with a response rate of $97.3 \%$. This is more than $100 \%$ of the power calculated sample size $(n=307)$. The reasons for non-responses were no time, not interested, unable to find their medical chart, and refusal to take visual acuity tests. The main socio-demographic characteristics of adults living with visual impairment in Gondar are shown in Table 1. The mean age of respondents was 56.46 ( $\mathrm{SD} \pm 14.2$ ) years and their age ranged from 25 to 89 years. Nearly, two-thirds of them (67.7\%) were in the age group 64 years and below. Among the 328 participants, the majority of them 189 (57.6\%) were males. More than half (59.1\%) of them were uneducated, almost four in five $(79.6 \%)$ were married, about two in five (42.2\%) had a monthly income of less than 1000 birr, and most of them (61.3\%) reported to have a good family or social support. About $70 \%$ of the participant's BMI category was normal weight followed by underweight (8.9\%). Only a few $(13.1 \%)$ reported being involved in physical exercise, a minority of them (10\%) were current smokers, and most of them (60.7) never consumed alcohol.

\section{Vision specific characteristics of the participants}

Among the total study subjects, more than one third 133 (40.5\%) of the patients were diagnosed with mild visually impaired based on Snell's E-chart reading. Of all the participants, 63(19.3\%) were diagnosed with severe visual impairment with presenting visual acuity $(<6 / 60$ to no light perception). Table 2 shows the vision-specific characteristics of the participants. The most common cause of visual impairments among the study participants was glaucoma (46.6\%) followed by refractive errors (19.3\%).

\section{Prevalence and distribution of fall among adults with visual impairment}

The prevalence and distribution of falls among adults with visual impairment are shown in Table 3. Eightyeight $(26.8,95 \%$ CI: $22.7,32.4 \%)$ visually impaired patients reported to have experienced at least one fall in the previous 12 months. Among those fallers, $14.8 \%$ of them reported having fallen more than once with the mean of $1.49( \pm 1.42)$ falls among 88 fallers. The maximum number of falls reported was 7 times by 3 participants. The prevalence of fall was nearly equal for male $(52.3 \%, n=46)$ as for female $(47.7 \%, n=42)$ participants. 
Table 1 Socio-demographic characteristics of adults living with visual impairment in Gondar, University Specialized Referral Hospital, Ethiopia $(n=328)$

\begin{tabular}{|c|c|c|c|c|c|}
\hline \multicolumn{3}{|c|}{ MUSpidal, L(IIIUpld $(I)=320)$} & \multicolumn{3}{|c|}{ 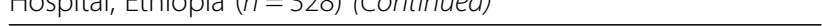 } \\
\hline Variables & Frequency & Percent (\%) & Variables & Frequency & Percent (\%) \\
\hline \multicolumn{3}{|l|}{ Sex } & \multicolumn{3}{|l|}{ Family/social support } \\
\hline Male & 189 & 57.6 & Yes & 201 & 61.3 \\
\hline Female & 139 & 42.4 & No & 127 & 38.7 \\
\hline \multicolumn{3}{|c|}{ Age in years (mean age $56.46 \pm 14.2$ ) } & \multicolumn{3}{|l|}{ Smoking habit } \\
\hline $18-44$ & 78 & 23.8 & Never & 313 & 95.4 \\
\hline $45-64$ & 144 & 43.9 & Past smoker & 5 & 1.5 \\
\hline$>64$ & 106 & 31.5 & Current smoker & 10 & 3 \\
\hline \multicolumn{3}{|l|}{ Residence } & \multicolumn{3}{|l|}{ Drinking alcohol habit } \\
\hline Urban & 135 & 41.2 & Never & 199 & 60.7 \\
\hline Rural & 193 & 58.8 & Past alcoholic & 39 & 11.9 \\
\hline \multicolumn{3}{|l|}{ Marital status } & Current alcoholic & 90 & 27.4 \\
\hline Not married & 10 & 3.0 & \multicolumn{3}{|l|}{ Physical exercise } \\
\hline Married & 261 & 79.6 & Yes & 43 & 13.1 \\
\hline Divorced & 31 & 9.5 & No & 285 & 86.9 \\
\hline Widowed & 26 & 7.9 & aily labor workers, stu & y mass Index & In birr \\
\hline
\end{tabular}

Religion

Orthodox
Protestants
Muslims
BMl $\left(\mathrm{kg} / \mathrm{m}^{2}\right)($ mean $19.94 \pm 2.15)$
Underweight $(<18.5)$
Normal $(18.5-24.9)$
Overweight $(25-29.9)$
Obese (> 29.9)
Occupation

Homemaker
Farmer
Civil servant
Merchant
Retired
Others $^{\mathrm{a}}$

Level of education

No formal school 194

Primary school 71

Secondary school 27

Diploma

Degree and above

Income (ETB/month)

$<1000$
$1000-2000$
$2001-3000$
$>3000$

Table 1 Socio-demographic characteristics of adults living with visual impairment in Gondar, University Specialized Referral Hospital, Ethiopia ( $n=328$ ) (Continued)

A significant difference was observed in previous 12 months self-reported fall prevalence between categories of fear of fall (not concerned 6.5\%, somewhat concerned $24.3 \%$, and very concerned $53.5 \% ; \chi^{2}(2, n=328)=72.9$, $p<0.001)$, phi $=0.47)$. Among the fallers, $19.1 \%$ of them reported having used some assistive mobility devices at the time of fall. Majority of the study participants were diagnosed with visual impairment in both their eyes and prevalence of fall was vastly different (one eye $7.9 \%$ versus both eyes $\left.32.5 \% ; x^{2}(1, \mathrm{n}=328)=18.1, \mathrm{p}<0.001\right)$, phi $=0.23$ ). The highest prevalence of fall was reported by adults those who are diagnosed with glaucoma $37(42.1 \%)$ followed by cataract $21(23.8 \%)$. Among the

Table 2 Vision specific characteristics of the participant in Gondar University Referral Hospital, Ethiopia $(n=328)$

\begin{tabular}{lll}
\hline Variables & Frequency(n) & Percent (\%) \\
\hline Cause of visual impairment & 34 & 10.4 \\
Cataract & 153 & 46.6 \\
Glaucoma & 25 & 7.6 \\
ARM & 13 & 4.0 \\
Diabetic retinopathy & 59 & 18.0 \\
URE & 44 & 13.4 \\
Others eye disease & & \\
Severity of visual impairment & 133 & 40.5 \\
Mild VI & 132 & 40.2 \\
Moderate VI & 63 & 19.3 \\
Severe VI
\end{tabular}

ARM age-related maculopathy, URE uncorrected refractive error, $\mathrm{VI}$ visual impairment 
Table 3 The self-reported prevalence of fall among adults with visual impairment in Gondar University Specialized Referral Hospital, Ethiopia

\begin{tabular}{|c|c|c|}
\hline \multirow[t]{2}{*}{ Variables } & \multicolumn{2}{|c|}{ Self-reported falls } \\
\hline & Yes $(\boldsymbol{n}=88)$ & No $(\boldsymbol{n}=240)$ \\
\hline \multicolumn{3}{|l|}{$\overline{\text { Sex }}$} \\
\hline Male & $46(52.3)$ & $143(59.6)$ \\
\hline Female & $42(47.7)$ & $97(40.4)$ \\
\hline \multicolumn{3}{|l|}{ Residence } \\
\hline Urban & $45(51.1 \%)$ & $90(37.5)$ \\
\hline Rural & $43(48.9 \%)$ & $150(63.5)$ \\
\hline \multicolumn{3}{|l|}{ Age in years } \\
\hline $18-44$ & $16(18.2)$ & $62(30.2)$ \\
\hline $45-64$ & 34 (38.6) & $110(45.8)$ \\
\hline$>64$ & $38(43.2)$ & $68(28.3)$ \\
\hline \multicolumn{3}{|l|}{$\mathrm{BMI}$ in $\mathrm{kg} / \mathrm{m}^{2}$} \\
\hline Underweight $(<18.5)$ & $27(30.7)$ & $52(21.7)$ \\
\hline Normal (18.5-24.9) & $55(62.5)$ & $176(73.3)$ \\
\hline Overweight (25-29.9) & $6(6.8)$ & $7(2.9)$ \\
\hline \multicolumn{3}{|l|}{ Marital status } \\
\hline Single not married & $4(4.5)$ & $8(3.3)$ \\
\hline Married & $60(68.2)$ & $201(83.7)$ \\
\hline Divorced & $8(9.1)$ & $23(9.7)$ \\
\hline Widowed & $16(18.2)$ & $8(3.3)$ \\
\hline \multicolumn{3}{|l|}{ Fear of fall } \\
\hline Not concerned & $8(9.1)$ & $115(47.9)$ \\
\hline Somewhat concerned & $26(29.5)$ & $81(33.7)$ \\
\hline Very concerned & $54(61.4)$ & $47(19.4)$ \\
\hline \multicolumn{3}{|l|}{ Severity of impairment } \\
\hline Mild visual impairment & $18(20.4)$ & $115(47.9)$ \\
\hline Moderate visual impairment & $39(43.3)$ & $93(38.7)$ \\
\hline Severe visual impairment & $31(35.3)$ & $32(13.3)$ \\
\hline \multicolumn{3}{|l|}{ Eye involved } \\
\hline One eye & $06(6.9)$ & $70(29.2)$ \\
\hline Both eyes & $82(93.1)$ & $170(70.8)$ \\
\hline \multicolumn{3}{|l|}{ Cause of Visual impairment } \\
\hline Cataract & $21(23.9)$ & $13(6.7)$ \\
\hline Glaucoma & $37(42.0)$ & $116(59.8)$ \\
\hline ARM & $8(9.1)$ & $17(8.8)$ \\
\hline Diabetic retinopathy & $10(11.4)$ & $3(1.5)$ \\
\hline URE & $8(9.1)$ & $5(2.6)$ \\
\hline Others eye disease & $4(4.5)$ & $40(20.6)$ \\
\hline \multicolumn{3}{|l|}{ Level of mobility } \\
\hline Independent without mobility aid & $56(63.6)$ & $209(87.1)$ \\
\hline Independent with mobility aid & $32(36.4)$ & $31(12.9)$ \\
\hline
\end{tabular}

$B M I$ body mass index, ARM age-related maculopathy, URE uncorrected refractive error participant who reported fall, most of them 63(70.8\%) had suffered one or more fall-related injuries.

\section{Factors associated with self-reported fall}

Table 4 shows the association between sociodemographic, psycho-social, visual related factors, clinical characteristics, and fall among the study participants. Fear of fall among the visually impaired participants was one of the main variables associated with fall in the regression model. Those participants who had reported that they are somewhat concerned about the fear of falling during ADL were 4.12 times more likely to fall as compared to participants not concerned fear of falling (AOR 4.12; 95\% CI, 1.44-11.76), The odds increase by $10.03(95 \% \mathrm{CI}, 3.03-33.21)$ if the participants reported to very worried or concerned about fall during ADL compared to those participants who had no concern about the fear of falling. The adjusted odds of fall were 4.63 times higher among people who had taken one or more medications as compared to their counterparts (AOR 4.63; 95\% CI 2.14-10.00). Participants with visual impairment in both their eyes were more than 3 times more likely to sustain fall than those with unilateral visual impairment (AOR 3.21, 95\% CI 1.11-9.29).

Visually impaired people who had depression were 3.46 times more likely to develop fall as compared to their counterparts (AOR 3.46; 95\% CI 1.11-10.79). The interaction effect between age and severity of visual impairment, age, and eye involved was not significant. Moreover, the causes of visual impairment were not associated $(p<0.2)$ with the outcome variable in the univariate logistic model (Additional file 3).

\section{Discussion}

The findings of this study showed that the overall prevalence of fall among visually impaired adult people was $26.8 \%$ with $95 \%$ CI (22.0-31.4). This implies that falls are a major public health problem, common reason for hospital trips in fall-related fractures, injuries (Table 2 in Additional file 3) and one of the main causes of disability among visually impaired people. This finding is harmonized with the studies conducted in Salisbury city in Maryland, USA, 28.9 and $27.8 \%$ respectively [25, 26], Cape Town, South Africa, 26\% [27] and Ibadan, Nigeria $23 \%$ [28]. This study found that the prevalence of fall among visually impaired adults increased with an increase in age, for age groups 18-44 years, 45-64 years and above 64 years the prevalence of fall in the past 12 months was $18.2,38.6$, and $43.2 \%$ respectively. Similarly, the study conducted in Latino, USA reported the prevalence of fall to be $18 \%$ in the age group 18-44 years age, $21 \%$ in $45-64$ years and $35 \%$ in older adults age greater than 64 years [2]. This could be due to physiological 
Table 4 Factors associated with fall among adults with visual impairment in Gondar University Specialized Referral Hospital, Ethiopia $(\mathrm{n}=328)$

\begin{tabular}{|c|c|c|c|c|}
\hline \multirow[t]{2}{*}{ Variables } & \multicolumn{2}{|c|}{ Self-reported fall } & \multirow{2}{*}{$\begin{array}{l}\text { Univariate COR } \\
(95 \% \mathrm{Cl})\end{array}$} & \multirow{2}{*}{$\begin{array}{l}\text { Multivariate AOR } \\
(95 \% \mathrm{Cl})\end{array}$} \\
\hline & Yes & No & & \\
\hline \multicolumn{5}{|l|}{ Age (years) } \\
\hline $18-44$ & 16 & 62 & $1.19(0.61-2.34)$ & $0.39(0.14-1.16)$ \\
\hline $45-64$ & 34 & 110 & $2.17(1.09-4.27)^{*}$ & $0.37(0.12-1.16)$ \\
\hline$>64$ & 38 & 68 & 1.00 & 1.00 \\
\hline \multicolumn{5}{|l|}{ Residence } \\
\hline Urban & 45 & 90 & 1.00 & 1.00 \\
\hline Rural & 43 & 150 & $0.57(0.35-0.94) *$ & $0.69(0.32-1.49)$ \\
\hline \multicolumn{5}{|l|}{ Fear of falling } \\
\hline Not at all concerned & 8 & 115 & 1.00 & 1.00 \\
\hline Somewhat concerned & 26 & 81 & $4.49(1.94-10.43) * *$ & $4.12(1.44-11.76) * *$ \\
\hline Very concerned & 54 & 47 & $16.08(7.11-36.4)^{* *}$ & $10.03(3.03-33.21)^{* *}$ \\
\hline \multicolumn{5}{|l|}{ Sleep disturbance } \\
\hline No & 48 & 203 & 1.00 & 1.00 \\
\hline Yes & 40 & 37 & $4.57(2.67-7.89) *$ & $1.62(0.73-3.58)$ \\
\hline \multicolumn{5}{|l|}{ Depression } \\
\hline No & 76 & 230 & 1.00 & 1.00 \\
\hline Yes & 12 & 10 & $3.6(1.51-8.74)^{* *}$ & $3.46(1.11-10.79) * *$ \\
\hline \multicolumn{5}{|c|}{ Severity of visual impairment } \\
\hline Mild & 18 & 115 & 1.00 & 1.00 \\
\hline Moderate & 39 & 93 & $0.16(0.08-0.33) *$ & $1.01(0.32-3.14)$ \\
\hline Severe & 31 & 32 & $0.43(0.23-0.79) *$ & $1.11(0.47-2.63)$ \\
\hline \multicolumn{5}{|l|}{ Visual impairment } \\
\hline One eye & 06 & 70 & 1.00 & 1.00 \\
\hline Both eyes & 82 & 170 & $5.62(2.35-13.49)^{*}$ & $3.21(1.11-9.29)^{*}$ \\
\hline \multicolumn{5}{|l|}{ Medication intake } \\
\hline No & 32 & 190 & 1.00 & 1.00 \\
\hline Yes & 56 & 50 & $6.65(3.89-11.35) * *$ & $4.63(2.14-10.00) * *$ \\
\hline \multicolumn{5}{|l|}{ Diabetes mellitus } \\
\hline No & 74 & 234 & 1.00 & 1.00 \\
\hline Yes & 14 & 6 & $7.38(2.42-19.88) *$ & $1.64(0.24-10.79)$ \\
\hline \multicolumn{5}{|l|}{ Hypertension } \\
\hline No & 72 & 231 & 1.00 & 1.00 \\
\hline Yes & 16 & 9 & $5.7(2.42-13.45) *$ & $1.85(0.55-6.17)$ \\
\hline
\end{tabular}

*variables significant with $p$-value $\leq 0.01$; ** variables significant with $p$-value $\leq 0.05,1=$ reference category; COR crude odds ratio, $A O R$ adjusted odds ratio, $C l$ confidence interval

change related to age, when the age increases the severity of visual impairment also increases, muscle and bone become deteriorated and weak so easily vulnerable for fall and fall-related injuries [29]. Surprisingly, in this study, there is neither association between fall and the severity of visual impairment nor correlation between the number of falls and severity of visual impairment, which is contrary to the findings elsewhere [30-32]. The possible reasons might be that the study area
(UOGCSH) is the only public ophthalmic clinic for the region and receives patients with a wide spectrum of eye diseases, from less severe to more severe. Besides, selfimposed restrictions and low level of mobility among participants with severe visual impairments could be other reasons for limited exposure and lesser falls. More notably, in LMICs like Ethiopia, people with visual disabilities face prejudice, stigma, limited job opportunities, 
inconvenient infra-structure, and lesser chance of exploring the environment.

However, the prevalence rate reported in this study is found to be lower when compared to studies conducted in USA 57.9\% [33] and Sweden 38\% [34]. This difference might be due to the difference in the study area, methodology, level of mobility of the participants, and the severity of visual impairments in the participant. The Sweden study was a community-based survey, the majority of their participants suffered a mild visual impairment and the mean age of their participants was much higher compared to this study probably due to higher life expectancy in the developed countries. In contrast, this study was institutional-based design, the mean age of our sample is much lesser, there is a difference in sample size, and variability in participant sociodemographic characteristics which might be the possible reasons for the difference in the estimates.

However, this finding is higher than other studies conducted elsewhere, in Malay, Singapore 14.7\% [35] in blue mountain eye study, Australia 16.1\% [31], and a prospective longitudinal study in Hong Kong, China 19.3\% [36]. The possible reason for this discrepancy might be the difference in sample size, study design, methods, infra-structural barriers in low-income countries, geographical terrain challenges of the study area, and economical and lifestyle variation. In particular, factors like difference in the educational level of the participants, availability of mobility aids, awareness program on risk factors and preventions, adjunct care in the eye clinic, and health-related facilities might also be the reasons for lower prevalence in these countries.

Another notable finding is that the fear of falling was an independent predictor of fall with higher odds of fall. It is also known that an actual fall leads to fear of falling syndrome and vice-versa [26]. This finding was supported by Salisbury, Maryland study [25]. This also suggests that fear of falling is not just an acute outcome that results from a fall; rather, it is likely recognition of being at risk and fear of falling leads to fall and viceversa. This could be due to the reasons that fear of falling leads to self-imposed restrictions like activity limitation, isolation, decrease the quality of life of the individual, loss of confidence, depression, result institutionalization and decreased physiological function leads to a high risk of fall and falling [14]. Moreover, fear of fall has gained acceptance as a very disabling medical issue and is present even in those who had never fallen before as a result of anticipatory anxiety. Thus, fear of falling shall be accounted for as one of the significant predictors of future falls.

Taking medications was also found to be one of the predictors of fall among visual impairment people in this study and should have more obvious implications for primary prevention strategies. This finding was supported by the study done in Salisbury, Maryland [25], and another cross-sectional study found that medication was significantly associated with fall among older adults [36]. The adverse effect of the medications, drug-drug interaction, metabolic effect of the drug on the body, and some antidepressants and antipsychotics can also cause fall secondary to orthostatic hypotension. In addition, those class of drugs that reduces the blood pressure or slows the heart can also contribute to falls [37, 38].

This study also showed that depression is associated with a two-fold higher risk of fall among visually impaired adults. Actual fall or fear of fall, visual impairment, and self-imposed mobility limitations could result in depression rather than depression being a casual or risk factor. The findings also suggest that depression prevention and treatment are a much-needed step towards fall prevention intervention [3, 39]. Moreover, there seems to be a web of causation between actual fall, fear of fall, and depression among visually impaired individuals.

Given that people with visual impairment in this study are at risk of fall and fear of fall, the findings emphasize the importance of addressing falls and fear of falling in this susceptible group. For the benefit of future researches, there are some noteworthy limitations. First, falls were self-reported with a recall period of 12 months and the potential recall bias was minimized by excluding participants with mild cognitive impairment. Second, confounders, unmeasured or unknown factors (societal or lifestyle) could have an influence on the findings. The cross-sectional nature of this study presents limitations in terms of causal association interpretations. For example, this study demonstrated the possible endogenous effect between fear of falling and falls. But the casual direction between these two variables cannot be explained. Other possible risk factors of fall like impaired muscle strength, vestibular, and postural impairments were not measured. The majority of the participants in this study could not recall the exact duration of visual impairment since diagnosis and therefore the association between adaptation to visual impairment and risk of fall is not known. Nevertheless, no prior study has directly examined the prevalence of fall in visually impaired people in Ethiopia and we strongly feel that these findings will provide more insight into the burden of fall in Ethiopia.

\section{Conclusions}

In summary, our findings from an adequately powered sample of visually impaired adults of Ethiopia document independent relationships between fear of fall, medication, depression, and falls in the past months. Other factors and confounders that may help explain fall in 
visually impaired adults, and the interaction between falls, fear of falling, loss of mobility, quality of life, and loss of confidence should be explored in future studies. Because each is a risk factor for the other, a person who has one of these factors is at risk for developing the other one. Fear of falling among visually impaired or any vulnerable individuals deserves special attention. In the meantime, health advocates and health policy providers are recommended to develop fall risk assessment, environment inspection, and modification, identify individuals at risk to educate them and provide fall-prevention treatments to avoid future fall and fall-related injuries.

\section{Supplementary information}

Supplementary information accompanies this paper at https://doi.org/10. 1186/s12889-020-08628-2.

Additional file 1. English version questionnaire.

Additional file 2. STROBE statement checklist.

Additional file 3. Additional table for univariate analysis of visual characteristics and fall, frequency distribution of fall-related injuries.

\section{Abbreviations}

ADL: Activities of daily living; AOR: Adjusted odds ratio; BMI: Body mass index; Cl: Confidence interval; COR: Crude odds ratio; CSA: Central Statistical Agency; CVD: Cardio-vascular disease; DM: Diabetes' Mellitus; FMOH: Federal Ministry of Health; HTN: Hypertension; LMIC's: Lower and Middle-Income Countries; OR: Odds ratio; TBI: Traumatic brain injuries; UOGH: University of Gondar Hospital; USA: United State of America; VI: Visual Impairment; WHO: World Health Organization

\section{Acknowledgments}

Firstly, we would like to express our deepest gratitude to the University of Gondar for ethical approval and funding. Our gratitude and appreciation go to data collectors and study participants without their cooperation this study would have not been possible.

\section{Author details}

MG is MSc and working as a Lecturer of Physiotherapy, School of Medicine, College of Medicine and Health Sciences, University of Gondar, Gondar, Ethiopia. BJ is MSc and working as an Assistant professor of Physiotherapy, School of Medicine, College of Medicine and Health Sciences and specialized hospital, University of Gondar, Gondar, Ethiopia.

AM is MPH and working as a Lecturer in the Department of Health System and Policy, Institute of Public Health, College of Medicine and Health Sciences, University of Gondar, Ethiopia.

GJ and KS are MSC and working as a Lecturer of Physiotherapy, School of Medicine, College of Medicine and Health Sciences, University of Gondar, Gondar, Ethiopia.

\section{Authors' contributions}

MG wrote the proposal, coordinated the data collection activity, analyzed the data and drafted the paper. BJ, AM, GJ, and KS revise the proposal and participated in the data collection, analysis, manuscript writing and review process. All authors read and approved the final manuscript.

\section{Funding}

This study was funded by the University of Gondar. The views presented in the article are the authors and not necessarily express the views of the funding organization. University of Gondar did not involve in the design of the study, data collection, analysis, and interpretation.

Availability of data and materials

Data will be available upon formal request from the corresponding author.

\section{Ethics approval and consent to participate}

After informing the purpose, benefits, risk, the confidentiality of the information and the voluntary nature of participants in the study, written consent were obtained from each of the participants, for participants with severe visual impairment and illiterate the consent form was read for them following which thumb impression was obtained. Name and personal identifiers were not included in the questionnaire. The participant's involvement in the study was on a voluntary basis and respondents were informed to refuse or stop at any point during the interview. Ethical clearance was obtained from the ethical review committee of the University of Gondar, College of Medicine and Health Sciences, from the school of medicine.

\section{Consent for publication}

Not applicable.

\section{Competing interests}

The authors declare that they have no conflict of interest.

\section{Author details}

${ }^{1}$ Department of Physiotherapy, School of Medicine, College of Medicine and Health Sciences, University of Gondar comprehensive specialized hospital, University of Gondar, P.O. Box: 196, Gondar, Ethiopia. ${ }^{2}$ Department of Health Systems and Policy, Institute of Public Health, College of Medicine and Health Sciences, University of Gondar, Gondar, Ethiopia.

Received: 31 October 2019 Accepted: 31 March 2020 Published online: 15 April 2020

\section{References}

1. Gazibara T, Kurtagic I, Kisic-Tepavcevic D, Nurkovic S, Kovacevic N, Gazibara $T$, et al. Falls, risk factors and fear of falling among persons older than 65 years of age. Psychogeriatrics. 2017;17(4):215-23.

2. Talbot LA, Musiol RJ, Witham EK, Metter EJ. Falls in young, middle-aged and older community dwelling adults: perceived cause, environmental factors and injury. BMC Public Health. 2005;5(1):86.

3. Dhital A, Pey T, Stanford MR. Visual loss and falls: a review. Eye. 2010;24(9): 1437.

4. Rosic G, Milston AM, Richards J, Dey P. Fear of falling in obese women under 50 years of age: a cross-sectional study with exploration of the relationship with physical activity. BMC Obes. 2019;6(1):7.

5. Bagley J. Predictors of fear of falling and activity avoidance in communitydwelling older adults; 2017.

6. Salomão SR, Mitsuhiro MR, Belfort R Jr. Visual impairment and blindness: an overview of prevalence and causes in Brazil. An Acad Bras Cienc. 2009;81(3): 539-49.

7. Flaxman S, Bourne R, Resnikoff S, Ackland P, Braithwaite T, Cicinelli M, et al. Global causes of blindness and distance vision impairment 19902020: a systematic review and meta-analysis. Lancet Glob Health. 2017; 5(12):e1221-34.

8. Dandona L, Dandona R. Revision of visual impairment definitions in the international statistical classification of diseases. BMC Med. 2006:4(1):7.

9. Cherinet FM, Tekalign SY, Anbesse DH, Bizuneh ZY. Prevalence and associated factors of low vision and blindness among patients attending St. Paul's Hospital Millennium Medical College, Addis Ababa, Ethiopia. BMC Ophthalmol. 2018;18(1):232.

10. Verma SK, Willetts JL, Corns HL, Marucci-Wellman HR, Lombardi DA Courtney TK. Falls and fall-related injuries among community-dwelling adults in the United States. PLoS one. 2016;11(3):e0150939.

11. Pattaramongkolrit S, Sindhu S, Thosigha O, Somboontanot W. Fall-related factors among older, visually-impaired Thais. Pac Rim Int J Nurs Res. 2013; 17(2):181-96.

12. Janakiraman B, Temesgen MH, Jember G, Gelaw AY, Gebremeskel BF, Ravichandran $\mathrm{H}$, et al. Falls among community-dwelling older adults in Ethiopia; A preliminary cross-sectional study. PLoS one. 2019;14;(9):e0221875.

13. Ramulu PY, Van Landingham SW, Massof RW, Chan ES, Ferrucci L, Friedman DS. Fear of falling and visual field loss from glaucoma. Ophthalmology. 2012;119(7):1352-8

14. Wang MY, Rousseau J, Boisjoly H, Schmaltz H, Kergoat M-J, Moghadaszadeh $\mathrm{S}$, et al. Activity limitation due to a fear of falling in older adults with eye disease. Invest Ophthalmol Vis Sci. 2012;53(13):7967-72. 
15. Yuki K, Tanabe S, Kouyama K, Fukagawa K, Uchino M, Shimoyama M, et al. The association between visual field defect severity and fear of falling in primary open-angle glaucoma. Invest Ophthalmol Vis Sci. 2013;54(12):773945.

16. Khanna RC, Marmamula S, Rao GN. International vision care: issues and approaches. Ann Rev Vis Sci. 2017;3:53-68.

17. O'Conor R, Smith SG, Curtis LM, Benavente JY, Vicencio DP, Wolf MS. Mild visual impairment and its impact on self-care among older adults. J Aging Health. 2018;30(3):327-41.

18. Kasiulevičius V, Šapoka V, Filipavičiūtè R. Sample size calculation in epidemiological studies. Gerontologija. 2006;7(4):225-31.

19. World Health Organization. WHO global report on falls prevention in older age. Geneva: World Health Organization (WHO); 200.

20. Makino K, Makizako H, Doi T, Tsutsumimoto K, Hotta R, Nakakubo S, et al. Impact of fear of falling and fall history on disability incidence among older adults: P rospective cohort study. Int J Geriatr Psychiatry. 2018;33(4):658-62.

21. Melton $F$, Horvat $M$, Ray $C$. Intrinsic and functional components of falls risk in older adults with visual impairments. Insight. 2011;4(2):66-73.

22. Abdelhafiz AH, Austin CA. Visual factors should be assessed in older people presenting with falls or hip fracture. Age Ageing. 2003;32(1):26-30.

23. Lord SR, Dayhew J. Visual risk factors for falls in older people. J Am Geriatr Soc. 2001;49(5):508-15.

24. da Mata LRF, Azevedo C, Policarpo AG, Moraes JT. Factors associated with the risk of fall in adults in the postoperative period: a cross-sectional study. Rev lat Am Enfermagem. 2017;25:e2904.

25. Crews JE, Chou C-F, Stevens JA, Saaddine JB. Falls among persons aged $\geq 65$ years with and without severe vision impairment-United States, 2014. Morb Mortal Wkly Rep. 2016;65(17):433-7.

26. Friedman SM, Munoz B, West SK, Rubin GS, Fried LP. Falls and fear of falling: which comes first? A longitudinal prediction model suggests strategies for primary and secondary prevention. J Am Geriatr Soc. 2002;50(8):1329-35.

27. Kalula SZ, Ferreira M, Swingler G, Badri M, Sayer AA. Prevalence of falls in an urban community-dwelling older population of Cape Town, South Africa. J Nutr Health Aging. 2015;19(10):1024-31.

28. Bekibele C, Gureje O. Fall incidence in a population of elderly persons in Nigeria. Gerontology. 2010;56(3):278-83.

29. Brundle C, Waterman HA, Ballinger C, Olleveant N, Skelton DA, Stanford P, et al. The causes of falls: views of older people with visual impairment. Health Expect. 2015;18(6):2021-31.

30. Coleman AL, Stone K, Ewing SK, Nevitt M, Cummings S, Cauley JA, et al. Higher risk of multiple falls among elderly women who lose visual acuity. Ophthalmology. 2004;111(5):857-62

31. Hong T, Mitchell P, Burlutsky G, Samarawickrama C, Wang JJ. Visual impairment and the incidence of falls and fractures among older people: longitudinal findings from the Blue Mountains eye study. Invest Ophthalmol Vis Sci. 2014;55(11):7589-93.

32. Klein BE, Moss SE, Klein R, Lee KE, Cruickshanks KJ. Associations of visual function with physical outcomes and limitations 5 years later in an older population: the beaver dam eye study. Ophthalmology. 2003;110(4):644-50.

33. Pineles SL, Repka MX, Yu F, Lum F, Coleman AL. Risk of musculoskeletal injuries, fractures, and falls in medicare beneficiaries with disorders of binocular vision. JAMA Ophthalmol. 2015;133(1):60-5

34. Källstrand-Eriksson J, Hildingh C, Bengtsson B. History of falling and visual ability among independently living elderly in Sweden. Clin Ophthalmol (Auckland). 2016;10:1265

35. Lamoreux EL, Chong E, Wang JJ, Saw SM, Aung T, Mitchell P, et al. Visual impairment, causes of vision loss, and falls: the Singapore Malay eye study. Invest Ophthalmol Vis Sci. 2008;49(2):528-33.

36. Chu L-W, Chi I, Chiu A. Incidence and predictors of falls in the Chinese elderly. Ann Acad Med Singap. 2005;34(1):60-72.

37. Milos V, Bondesson Å, Magnusson M, Jakobsson U, Westerlund T, Midlöv P. Fall risk-increasing drugs and falls: a cross-sectional study among elderly patients in primary care. BMC Geriatr. 2014;14(1):40.

38. Campbell AJ, Robertson MC, Gardner MM, Norton RN, Buchner DM. Psychotropic medication withdrawal and a home-based exercise program to prevent falls: a randomized, controlled trial. J Am Geriatr Soc. 1999;47(7): 850-3.

39. Byers AL, Sheeran T, Mlodzianowski AE, Meyers BS, Nassisi P, Bruce ML. Depression and risk for adverse falls in older home health care patients. Res Gerontol Nurs. 2008:1(4):245-51.

\section{Publisher's Note}

Springer Nature remains neutral with regard to jurisdictional claims in published maps and institutional affiliations.
Ready to submit your research? Choose BMC and benefit from:

- fast, convenient online submission

- thorough peer review by experienced researchers in your field

- rapid publication on acceptance

- support for research data, including large and complex data types

- gold Open Access which fosters wider collaboration and increased citations

- maximum visibility for your research: over $100 \mathrm{M}$ website views per year

At BMC, research is always in progress.

Learn more biomedcentral.com/submissions 